\title{
Influence of Milling Conditions on the Hydriding Properties of $\mathrm{Mg}-\mathrm{C}$ Nanocomposites
}

\author{
Hristina Stoyadinova, ${ }^{1}$ Zlatina Zlatanova, ${ }^{1}$ Maya Spassova, \\ Tony Spassov, ${ }^{1}$ and Mikhail Baklanov ${ }^{2}$ \\ ${ }^{1}$ Faculty of Chemistry and Pharmacy, University of Sofia "St. Kliment Ohridski", 1 James Bourchier Street, 1164 Sofia, Bulgaria \\ ${ }^{2}$ Interuniversity Micro-Electronics Center at Leuven, IMEC, 3001 Leuven, Belgium
}

Correspondence should be addressed to Tony Spassov; tspassov@chem.uni-sofia.bg

Received 23 December 2014; Accepted 17 January 2015

Academic Editor: Antonios Kelarakis

Copyright (C) 2015 Hristina Stoyadinova et al. This is an open access article distributed under the Creative Commons Attribution License, which permits unrestricted use, distribution, and reproduction in any medium, provided the original work is properly cited.

\begin{abstract}
Mg75 at.\%, CB25 at.\% (CB: carbon black) composites were synthesized at different ball milling conditions (milling energy, milling duration, and environment) and their hydriding properties were characterized by high-pressure DSC. The SEM observations revealed that the samples consist of 5-15 $\mu \mathrm{m} \mathrm{Mg}$ particles, surrounded and in some cases coated by carbon particles. X-ray diffraction analysis showed that the $\mathrm{Mg}$ phase of all as-obtained composite powders is nanocrystalline with average crystallite size in the range $20-30 \mathrm{~nm}$, depending on the milling conditions. The best hydriding properties, expressed in low-temperature hydriding (below $150^{\circ} \mathrm{C}$ ) and improved cycle life, showed the composites milled at dry conditions. This is obviously due mainly to the successful $\mathrm{Mg}$ surface protection by the carbon. Additional decrease of the hydriding temperature $\left(<100^{\circ} \mathrm{C}\right)$ was achieved applying higher-energy milling, but at the same time the cycling stability deteriorated, due to the extremely fine particles and microstructure achieved under these conditions. The composites milled in the presence of heptane showed rapid capacity decline during cycling as well. The observed difference in the hydriding behavior of the Mg-CB composites is attributed to the different coating efficiency of the carbon milled under different conditions with $\mathrm{Mg}$, which is supposed to protect magnesium from oxidation and plays a catalytic role for the hydriding reaction.
\end{abstract}

\section{Introduction}

The effect of different forms of carbon on the hydriding properties of ball-milled $\mathrm{Mg}-\mathrm{C}$ composites has been an object of various studies in the last years [1-16]. Graphite, activated carbon, carbon nanotubes (CNTs), multiwalled carbon nanotubes (MWCNTs), and carbon fibers were investigated with the aim to decrease the $\mathrm{MgH}_{2}$ decomposition temperature [1] as well as improving the hydriding/dehydriding kinetics [3]. The best results for the $\mathrm{MgH}_{2}$ with CNTs and MWCNTs with metallic impurities were reported by Lillo-Ródenas et al. [1]. They also found a clear relation between the $\mathrm{MgH}_{2}$ decomposition temperature and its microstructure. The presence of carbon was reported to prevent the $\mathrm{MgH}_{2}$ particle growth, which, in turn, enhances its decomposition. Improvement of $\mathrm{H}$-sorption in ball-milled $\mathrm{Mg} / \mathrm{MgH}_{2}$ using expanded natural graphite (ENG) has also been reported
[2]. Although the thermodynamic properties and intrinsic hydrogen sorption kinetics were found to remain unchanged the ENG incorporation reduces the hydrogen permeability [2].

Among the various carbon additives purified singlewalled carbon nanotubes (SWNTs) were reported to exhibit the most prominent "catalytic" effect on the hydriding of Mg. Under the same conditions, hydrogen sorption rates of Mgcarbon systems were found to be one order of magnitude higher than that of pure $\mathrm{Mg}$ [4].

Montone et al. [5] reported that the presence of benzene in the milled $\mathrm{Mg}-\mathrm{C}$ blends induces a finer powder particle size and results in a complete transformation of the milled powder to the hydride by thermal reaction with hydrogen gas. Imamura et al. have also proposed the application of Mg-graphite nanocomposites, produced by ball milling with different organic additives (tetrahydrofuran, cyclohexane, 
and benzene) as new hydrogen storage materials [6-8]. They reported about the possibility for the formation of new sites for hydrogen storing other than those due to the magnesium, able to store hydrogen reversibly [6].

Recent promising theoretical study of Kim et al. [17] predicts the effect of the nanoparticle size on the thermodynamics of hydrogen release from $\mathrm{MgH}_{2}$. The authors found that for $\mathrm{MgH}_{2}$ particles below $10 \mathrm{~nm}$ the hydride phase is thermodynamically destabilized, resulting in pronounced lowering of the decomposition temperature [17].

$\mathrm{MgH}_{2} 75$ at.\%, C 25 at.\% nanocomposites, synthesized by ball milling using different kinds of carbon additives (carbon black, nanodiamonds, and amorphous carbon soot), have been objects of our recent study [18]. The composite containing nanodiamonds revealed strong decrease of the $\mathrm{MgH}_{2}$ decomposition temperature with more than $100^{\circ} \mathrm{C}$, compared to ball-milled $\mathrm{MgH}_{2}$. The incorporation of carbon into the surface of the $\mathrm{MgH}_{2} / \mathrm{Mg}$ particles and thus the creation of high density of phase boundaries were found to form new easy accessible hydrogen atoms sites and enhance the diffusion of hydrogen into the magnesium grains. Among the composites in the previous study $\mathrm{Mg}-\mathrm{CB}$ revealed the best overall hydriding characteristics, low temperature of hydriding in a relatively narrow temperature range by a single-step reaction and fast hydriding kinetics at relatively low temperatures $\left(<300^{\circ} \mathrm{C}\right)$. Possible explanation of the improved dehydriding behavior of this composite is the fine particle and grain size and better contact between the carbon and $\mathrm{MgH}_{2} / \mathrm{Mg}$ particles compared to the other Mg$\mathrm{C}$ materials studied. Therefore the aim of the present work was to study the hydriding properties of Mg-CB (CB-carbon black) nanocomposites prepared at substantially different ball milling conditions. Carbon black was selected as a composite component on the base of our previous study revealing its advantages among a series of carbon additives (graphite, ND, $\mathrm{CB}$, and amorphous carbon) [18].

\section{Experimental Details}

The composites with a composition of Mg 75 at. \%, CB 25 at.\% (CB: carbon black) were synthesized by high-energy ball milling, by Fritsch planetary equipment (Pulverisette 6) at $350 \mathrm{rpm}$, using stainless steel vials and balls at weight ratio of ball to metal powders of $12: 1$. A custom built planetary ball mill [19] was also used for some of the syntheses. This mill was found to perform approximately 10 times more intensive milling than Fritch P5. The milling process with both mills was carried out for different time with 1 hour of continuous milling, followed by 15 minutes relaxation time. Protective atmosphere of pure Ar (99.999\%) was used and the pressure within the vials was kept over 1 bar to preserve the purity of the gas. Initial materials, used for the synthesis, were pure $\mathrm{Mg}$ or $\mathrm{MgH}_{2}$ powders and carbon black (VULCAN XC72R, CABOT Corp.).

Microstructural information was obtained by XRD, using Bruker D8 Advance diffractometer with $\mathrm{Cu}-\mathrm{K} \alpha$ radiation. Morphology and particle size distribution were observed by Scanning Electron Microscope JEOL 5510.
TABLE 1: Composition and conditions of milling of the $\mathrm{Mg}-\mathrm{CB}$ composites ( $\mathrm{Mg}: \mathrm{CB}=75: 25$ at. $\%)$.

\begin{tabular}{lcc}
\hline Starting mixture & Time, $\mathrm{c}$ & $\begin{array}{c}\text { Antisticking agent } \\
\text { (heptane) }\end{array}$ \\
\hline $\mathrm{Mg}-\mathrm{CB}$ & 15 & Yes \\
$\mathrm{Mg}-\mathrm{CB}$ & 35 & Yes \\
$\mathrm{Mg}-\mathrm{CB}$ & 35 & No \\
$\mathrm{Mg}^{-\mathrm{CB}}$ & 15 (high energy mill) & Yes \\
$\mathrm{MgH}_{2}-\mathrm{CB}$ & 35 & No \\
\hline
\end{tabular}

The hydriding/dehydriding processes were studied by high-pressure differential scanning calorimetry (HPDSC), SETARAM Sensys Evo TG-DSC. PARSTAT 2273 electrochemical system and $6 \mathrm{M} \mathrm{KOH}$ water solution electrolyte were used for proving the composites hydrogen charge/discharge behaviour at galvanostatic conditions.

\section{Results and Discussion}

Mg75-C25 (at.\%) composites with the same composition were prepared at different conditions, Table 1 . The first two composites were milled in the presence of heptane for different time (15 and $35 \mathrm{~h}$ ). The third $\mathrm{Mg}-\mathrm{C}$ composite was milled at dry conditions (in the absence of heptane) for $35 \mathrm{~h}$. A self-constructed high energy mill [19] was applied for the synthesis of the fourth composite. The last composite with the same composition was prepared at the same milling conditions (35 h milling at dry conditions), but using different initial $\mathrm{Mg}$ compound $\left(\mathrm{MgH}_{2}\right.$ instead of pure $\left.\mathrm{Mg}\right)$, Table 1.

The morphology of the investigated ball-milled powder composites is shown in Figure 1. On the micrographs particles with different morphology and size, depending on the milling conditions, can be detected. The composite milled with higher energy is characterized by slightly smaller particle size. Milling at dry conditions also results in particles size reduction compared to the composites prepared with the presence of heptane. Comparing the composites produced from $\mathrm{Mg}$ and $\mathrm{MgH}_{2}$ as starting materials it is evident that the hydride leads to smaller particle size. For all composites at larger magnification it is clearly seen that the particles are agglomerations of much smaller ones and are uniformly covered by very small carbon particles.

Figure 2 presents the X-ray diffractograms of the studied $\mathrm{Mg}-\mathrm{C}$ composites. Except the peaks of $\mathrm{Mg}$ some of the diffractograms contain also more intensive peaks of $\mathrm{MgO}$, as the $\mathrm{MgO}$ diffraction peaks of the materials milled at dry conditions and from $\mathrm{MgH}_{2}$ are noticeably smaller. As expected, increasing the milling duration leads to decrease in the grain size. It is interesting to mention that milling for $15 \mathrm{~h}$ in the high energy mill leads to smaller grain size $(\sim 15 \mathrm{~nm})$ compared to the $35 \mathrm{~h}$ milled in the conventional mill (Fritsch P6) sample $(\sim 30 \mathrm{~nm})$, but at the same time the amount of the oxide $(\mathrm{MgO})$ increases as well. The last is due to the highly developed very active $\mathrm{Mg}$ particles surface, which reacts with oxygen even during the powders handling under air atmosphere. From the X-ray pattern of the composites 


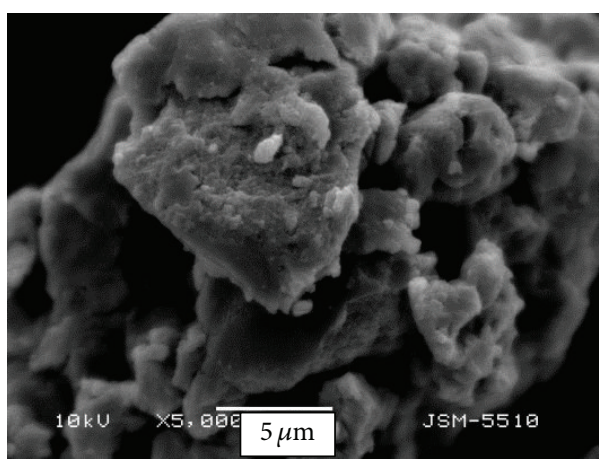

(a)

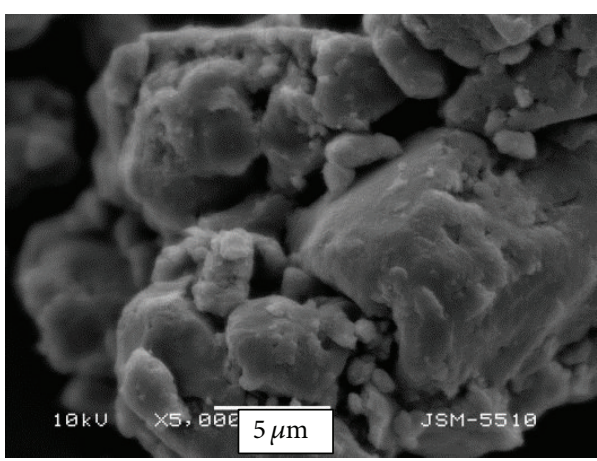

(c)

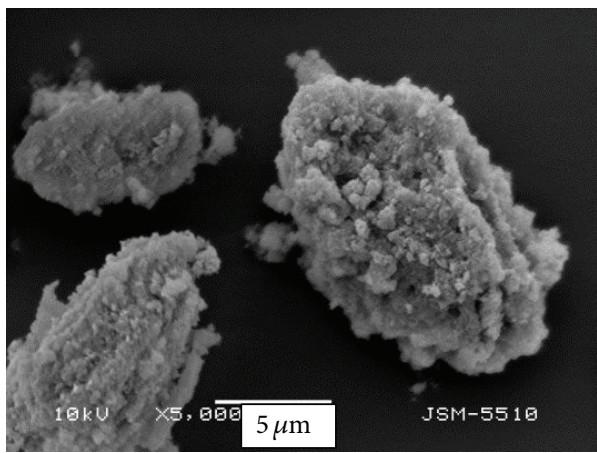

(e)

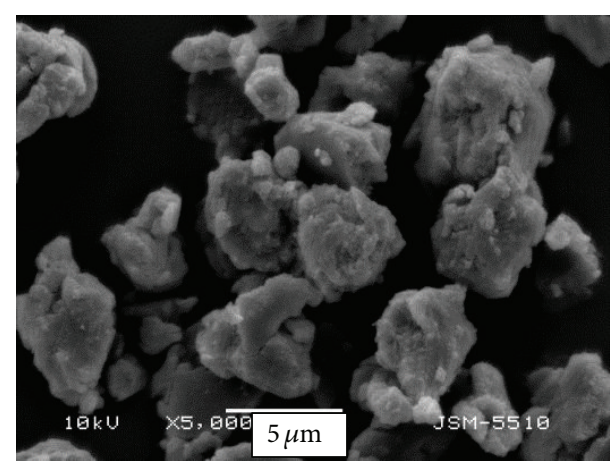

(b)

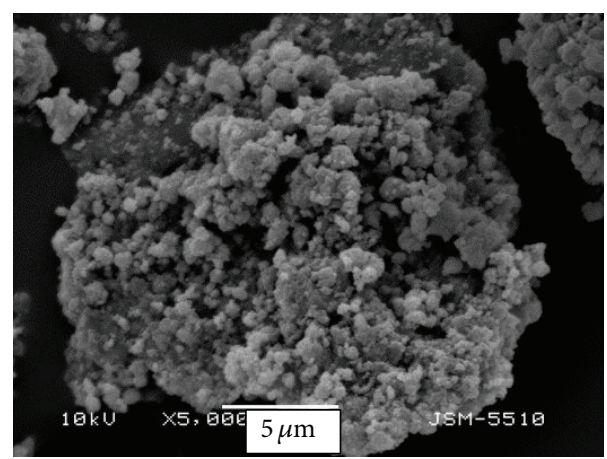

(d)

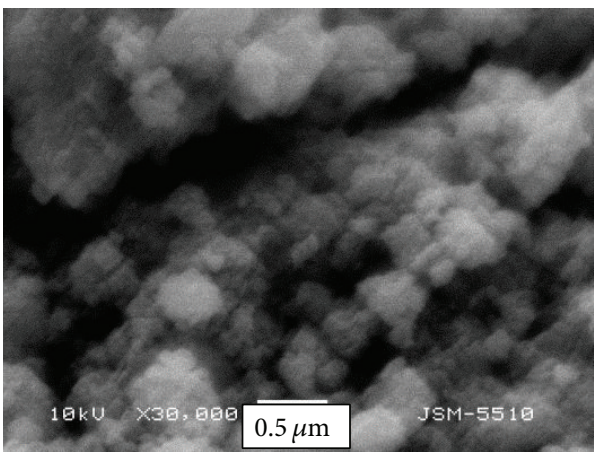

(f)

Figure 1: SEM micrographs of (a) Mg-CB (15 h milling in heptane), (b) Mg-CB (35 h milling in heptane), (c) Mg-CB (35 h dry milling), (d) $\mathrm{Mg}-\mathrm{CB}$ (15 h milling with high energy mill), (e) $\mathrm{MgH}_{2}-\mathrm{CB}$ composites, and (f) $\mathrm{Mg}-\mathrm{CB}$ (15 h milling with high energy mill).

milled from $\mathrm{MgH}_{2}$ it is obvious that the milling results in $\mathrm{Mg}$ crystals size reduction $\left(\mathrm{MgH}_{2}\right.$ decomposes during the milling under these conditions). Formation of new phases due to the milling was not detected even applying high energy of milling and long time of the treatment.

To determine the temperature and heat of $\mathrm{Mg}$ hydriding and $\mathrm{MgH}_{2}$ decomposition as well as studying the hydriding and dehydriding processes at different hydrogen pressures high-pressure DSC (HP-DSC) analyses with constant heating and cooling rates were carried out. Figure 3 shows the HPDSC thermograms under a pressure of 25 bars hydrogen and a linear temperature scan of the $\mathrm{Mg}-\mathrm{CB}$ composites (milled under different conditions conditions). They all reveal a broad exothermic effects in the temperature range of 100$350^{\circ} \mathrm{C}$ (depending on the milling conditions) due to hydrogen absorption and hydriding of magnesium to $\mathrm{MgH}_{2}$, proved by
XRD analysis after annealing in the DSC up to $350^{\circ} \mathrm{C}$ under hydrogen atmosphere [18]. From the measured heat released during the hydriding (enthalpy change due to hydriding) it can be concluded that under the conditions applied in the DSC ( 25 atm $\mathrm{H}_{2}$, heating rate $5 \mathrm{~K} / \mathrm{min}$ ) the samples were not completely hydrided, that is, part of the inner volume of the $\mathrm{Mg}$ particles does not react with hydrogen. Rough estimation of the hydrided part gives a value of about $60 \%$. This result is confirmed by the enthalpies determined from the endothermic DSC peaks of the $\mathrm{MgH}_{2}$ decomposition registered during continuous heating of the hydrided samples as well as the exothermic peaks result of the repeated hydriding of $\mathrm{Mg}$ through cooling the decomposed composites, Figure 4.

Because the main idea of this work was to study the influence of the milling conditions on the hydriding/dehydriding behavior of $\mathrm{Mg}-\mathrm{C}$ nanocomposites revealed at usual ambient 


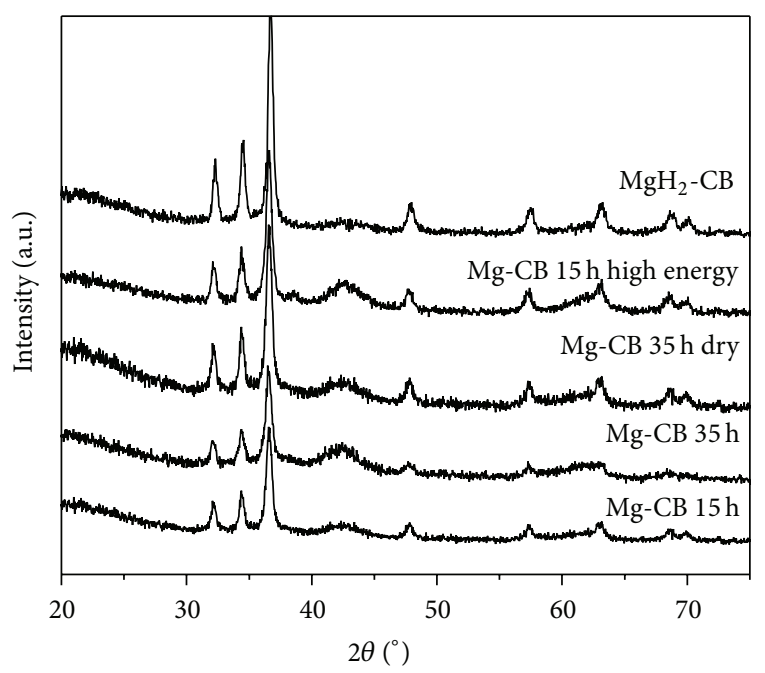

FIGURE 2: XRD patterns of the different ball-milled composites.

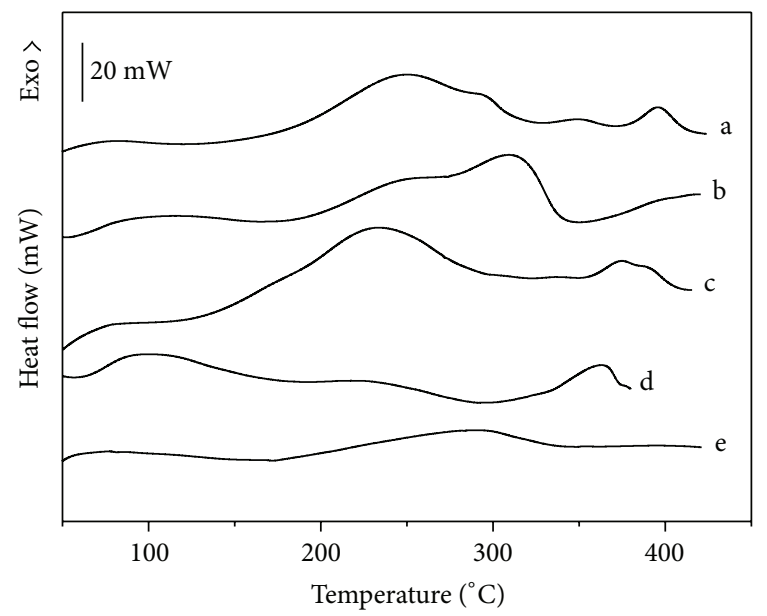

FIGURE 3: High-pressure DSC plots ( $25 \mathrm{bars}, 5 \mathrm{~K} / \mathrm{min}$ ) for the $\mathrm{Mg}$ CB composites ((a) milled $15 \mathrm{~h}$ with heptane, (b) $35 \mathrm{~h}$ milled with heptane, (c) $35 \mathrm{~h}$ milled at dry conditions, (d) $15 \mathrm{~h}$ high energy milled, and (e) milled from $\mathrm{MgH}_{2}$ ).

conditions (in atmosphere containing oxygen) in Figure 4 the hydriding behavior of two composites is compared, ballmilled for the same time $(35 \mathrm{~h})$ under 2 different environments: in heptane and at dry conditions. It is evident that the composite milled in heptane shows worse hydriding behavior compared to the other two composites milled entirely or partially at dry conditions. This result could only be explained by the blocked particles surface due to Mg oxidation; that is, under these conditions of milling (in heptane as antisticking agent) the surface of the $\mathrm{Mg}$ particles is not protected by the carbon. The same low cycling stability was observed for all composites milled in the presence of heptane (milled for $15 \mathrm{~h}$ and $35 \mathrm{~h}$ and in the high energy mill). The behavior of the dry milled composite is completely different (prepared by milling for the same time, but without heptane), Figure 4 . In contrast to the composite milled in the presence of heptane the dry milled material not only reveals improved first hydriding/dehydriding reaction, but also shows stability during repeated hydriding and dehydriding (Figure 5). Both the heat released during hydriding $(900 \mathrm{~J} / \mathrm{g})$ and that absorbed during the hydride decomposition $(920 \mathrm{~J} / \mathrm{g})$ do not change noticeably after the 5th cycle. The two strongly overlapped endothermic peaks of $\mathrm{MgH}_{2}$ decomposition for the composite milled in heptane (Figure 4(b)) are most probably due to the presence of metastable $\gamma-\mathrm{MgH}_{2}$ together with the stable at these conditions tetragonal $\beta-\mathrm{MgH}_{2}$. It was shown that during ball milling this metastable phase can be formed and its thermal stability is slightly lower than that of $\beta-\mathrm{MgH}_{2}[16,20,21]$.

Another possible way for significant influence on the composite hydriding properties could be a large increase of the milling energy, realized in our study by using a high energy self-designed mill [19]. In this case the composites are characterized with finer particles (average size less than $1 \mu \mathrm{m})$ and reduction of the crystallite size compared to the other composites, Figures 1 and 2. The influence of the finer microstructure on the hydriding is obvious (Figure 3 ). The process of hydriding starts at temperatures lower than $100^{\circ} \mathrm{C}$. At the same time, however, the cycling stability strongly worsens, due to the very reactive surface created under these conditions.

Using $\mathrm{MgH}_{2}$ instead of $\mathrm{Mg}$ as starting material for $\mathrm{Mg}-\mathrm{CB}$ composite preparation results also in particles size reduction, compared to the composites produced by milling the metal with carbon black (see Figure 1), but under the synthetic conditions applied in the present study this does not reflect in noticeable hydriding properties improvement (Figure 3).

As expected the temperature of the hydrides decomposition and of subsequent hydriding during cooling the dehydrided composites under hydrogen atmosphere from $500^{\circ} \mathrm{C}$ is almost the same for all composites studied. This result shows that the thermodynamics of hydriding/dehydriding is not changed by the mechanical treatments applied in the study, Figure 4 . What is really improved is the cycling stability of the nanocomposites milled at dry conditions due to better $\mathrm{Mg}$ surface protection by carbon. Although the milling at dry conditions leads to some decrease of the average crystallite size compared to the samples milled in the presence of heptane, the difference, observed in the hydriding/dehydriding behavior of these composites, has to be attributed to their qualitatively better surface protection by the carbon, improving the kinetics of low-temperature hydriding and their hydriding/dehydriding cycling stability. The observed difference can only be explained by the surface properties of the milled with carbon at dry-conditions magnesium particles, obviously connected with better coating conditions realized in this case. Milling at dry conditions clearly promotes the formation of better contact between carbon and $\mathrm{Mg}$ particles in a much larger degree compared to the composites prepared in the presence of heptane.

Additional information about the decomposition temperature of the $\mathrm{MgH}_{2}$ for the different $\mathrm{Mg}$-C composites was also obtained by DSC analysis under low vacuum $\left(0.1 \mathrm{~atm} . \mathrm{H}_{2}\right)$, Figure 6. Temperature of decomposition of about $270-280^{\circ} \mathrm{C}$ and enthalpy change equal to those determined under hydrogen pressure were registered. Under low vacuum the hydrides 


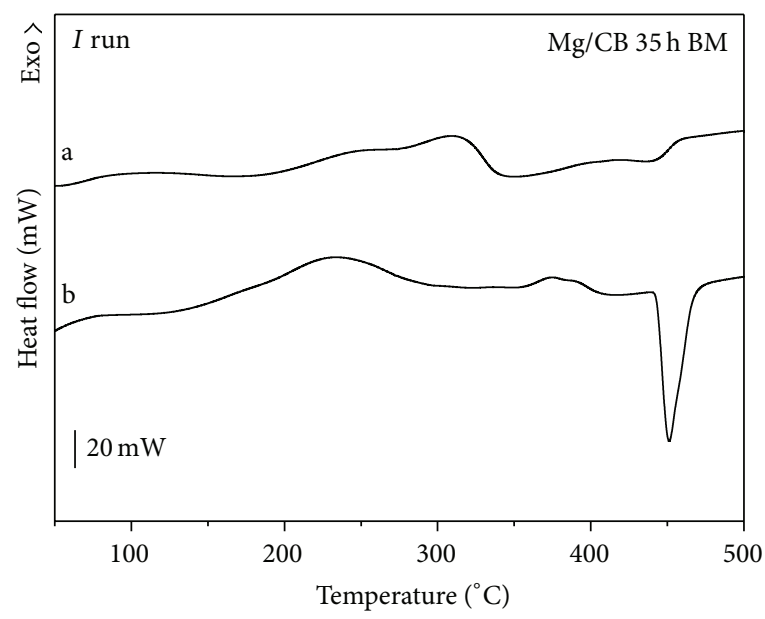

(a)

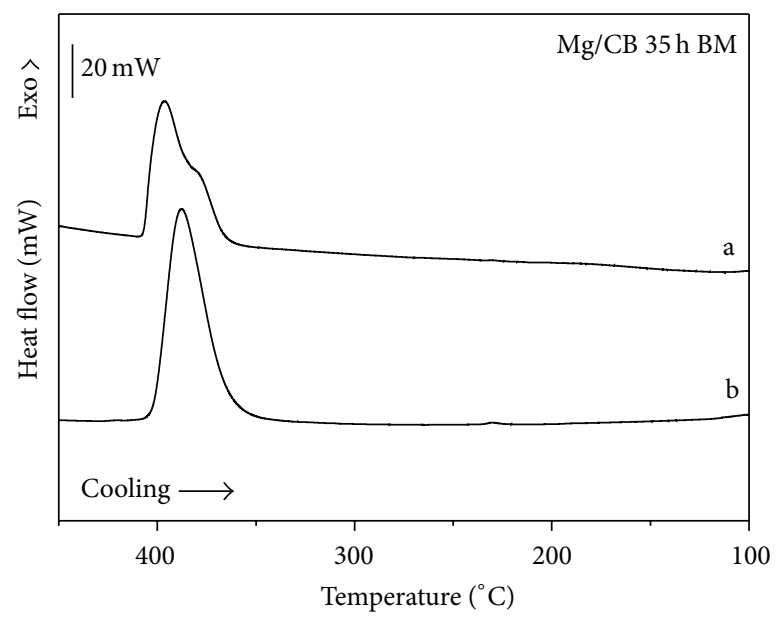

(b)

FIGURE 4: High-pressure DSC plots of Mg-CB composites milled at dry conditions and with heptane under hydrogen pressure of 25 bars: (a) heating and (b) cooling.



FIGURE 5: $V$ th cycle of hydriding and dehydriding under hydrogen pressure of 25 bars: (a) $35 \mathrm{~h}$ milled with heptane and (b) $35 \mathrm{~h}$ milled at dry conditions.

formed in the "dry milled" Mg-C composites decompose at lower temperature, compared to that for the material milled in heptane, Figure 6.

To prove the ability of the best performing composite (with improved hydriding kinetics and cycle life) to be electrochemically hydrided and dehydrided hydrogen charge/discharge experiments have also been carried out at galvanostatic conditions. According to the expectations, even the composite with the best hydriding characteristics does not show reversible hydrogen charge/discharge, obviously, a result of the high stability of $\mathrm{MgH}_{2}$.

\section{Conclusions}

Mg-CB (CB: carbon black) nanocomposites with different morphology and microstructure were prepared by ball

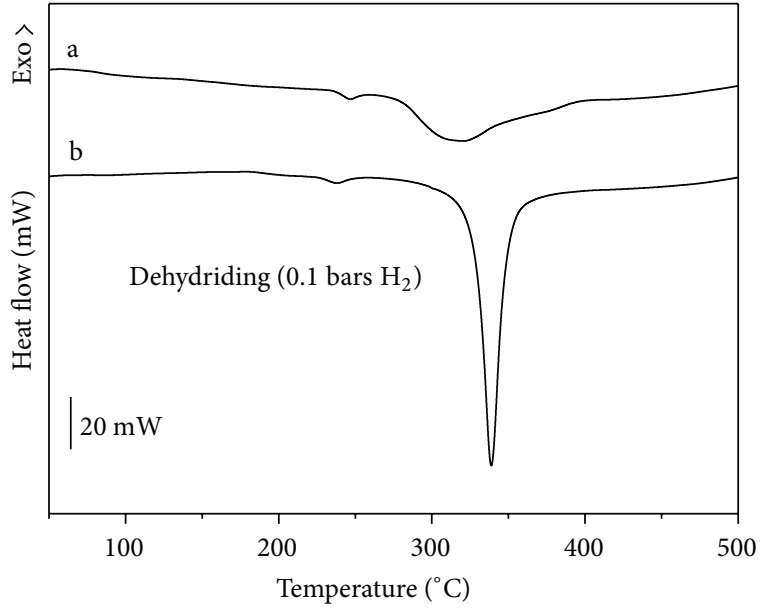

Figure 6: Decomposition (0.1 bars) of the hydrided Mg-CB composite during heating in DSC with $5 \mathrm{~K} / \mathrm{min}$ : (a) $35 \mathrm{~h}$ milled with heptane and (b) $35 \mathrm{~h}$ milled at dry conditions.

milling, varying key milling parameters (energy, time, and environment of milling) and their hydriding/dehydriding properties were compared. The composites milled at dry conditions (without antisticking agent) revealed significant improvement of the hydriding kinetics at low temperatures $\left(<150^{\circ} \mathrm{C}\right)$ as well as their hydriding/dehydriding cycle stability, obviously due to the successful $\mathrm{Mg}$ surface protection, resulting in facilitated hydrogen diffusion into the $\mathrm{Mg}$ grains. Milling at dry conditions clearly promotes the formation of better contact between carbon and $\mathrm{Mg}$ particles in a much larger degree compared to the composites prepared in the presence of heptane. In contrast, the composites milled in the presence of heptane showed rapid capacity deterioration during cycling, revealing a nonefficient carbon coating process. Another interesting issue of the present study is that the composite milled in a high energy mill 
is characterized by extremely low temperature of hydriding $\left(<100^{\circ} \mathrm{C}\right)$, but its cycling stability is very low, as the reason for these properties is the finer particles and microstructure and worse magnesium particles coating by carbon achieved under these conditions.

\section{Conflict of Interests}

The authors declare that there is no conflict of interests regarding the publication of this paper.

\section{Acknowledgments}

The work has been supported by FP7 BeyondEverest project. The authors acknowledge the support of the COST Action MP1103.

\section{References}

[1] M. A. Lillo-Ródenas, Z. X. Guo, K. F. Aguey-Zinsou, D. CazorlaAmorós, and A. Linares-Solano, "Effects of different carbon materials on $\mathrm{MgH}_{2}$ decomposition," Carbon, vol. 46, no. 1, pp. 126-137, 2008.

[2] A. Chaise, P. de Rango, P. Marty et al., "Enhancement of hydrogen sorption in magnesium hydride using expanded natural graphite," International Journal of Hydrogen Energy, vol. 34, no. 20, pp. 8589-8596, 2009.

[3] A. D. Rud, A. M. Lakhnik, V. G. Ivanchenko et al., "Hydrogen storage of the Mg-C composites," International Journal of Hydrogen Energy, vol. 33, no. 4, pp. 1310-1316, 2008.

[4] C. Z. Wu, P. Wang, X. Yao et al., "Effect of carbon/noncarbon addition on hydrogen storage behaviors of magnesium hydride," Journal of Alloys and Compounds, vol. 414, no. 1-2, pp. 259-264, 2006.

[5] A. Montone, J. Grbović, A. Bassetti et al., "Microstructure, surface properties and hydrating behaviour of $\mathrm{Mg}$-C composites prepared by ball milling with benzene," International Journal of Hydrogen Energy, vol. 31, no. 14, pp. 2088-2096, 2006.

[6] H. Imamura, S. Tabata, N. Shigetomi, Y. Takesue, and Y. Sakata, "Composites for hydrogen storage by mechanical grinding of graphite carbon and magnesium," Journal of Alloys and Compounds, vol. 330-332, pp. 579-583, 2002.

[7] H. Imamura, S. Tabata, Y. Takesue, Y. Sakata, and S. Kamazaki, "Hydriding-dehydriding behavior of magnesium composites obtained by mechanical grinding with graphite carbon," International Journal of Hydrogen Energy, vol. 25, no. 9, pp. 837-843, 2000.

[8] H. Imamura, M. Kusuhara, S. Minami et al., "Carbon nanocomposites synthesized by high-energy mechanical milling of graphite and magnesium for hydrogen storage," Acta Materialia, vol. 51, no. 20, pp. 6407-6414, 2003.

[9] J. Huot, M.-L. Tremblay, and R. Schulz, "Synthesis of nanocrystalline hydrogen storage materials," Journal of Alloys and Compounds, vol. 356-357, pp. 603-607, 2003.

[10] C. X. Shang and Z. X. Guo, "Effect of carbon on hydrogen desorption and absorption of mechanically milled $\mathrm{MgH}_{2}$," Journal of Power Sources, vol. 129, no. 1, pp. 73-80, 2004.

[11] R. V. Lukashev, S. N. Klyamkin, and B. P. Tarasov, "Preparation and properties of hydrogen-storage composites in the $\mathrm{MgH}_{2}-\mathrm{C}$ system," Inorganic Materials, vol. 42, no. 7, pp. 726-732, 2006.
[12] Z. G. Huang, Z. P. Guo, A. Calka et al., "Noticeable improvement in the desorption temperature from graphite in rehydrogenated $\mathrm{MgH}_{2}$ /graphite composite," Materials Science and Engineering A, vol. 447, no. 1-2, pp. 180-185, 2007.

[13] J.-L. Bobet, E. Grigorova, M. Khrussanova et al., "Hydrogen sorption properties of graphite-modified magnesium nanocomposites prepared by ball-milling," Journal of Alloys and Compounds, vol. 366, no. 1-2, pp. 298-302, 2004.

[14] D. Chen, L. Chen, S. Liu, C. X. Ma, D. M. Chen, and L. B. Wang, "Microstructure and hydrogen storage property of Mg/MWNTs composites," Journal of Alloys and Compounds, vol. 372, no. 1-2, pp. 231-237, 2004.

[15] A. D. Rud and A. M. Lakhnik, "Effect of carbon allotropes on the structure and hydrogen sorption during reactive ball-milling of Mg-C powder mixtures," International Journal of Hydrogen Energy, vol. 37, no. 5, pp. 4179-4187, 2012.

[16] E. Grigorova, M. Spassova, M. Khristov, B. Tsyntsarski, and T. Spassov, "High-pressure DSC study on the hydriding and dehydriding of $\mathrm{Mg} / \mathrm{C}$ nanocomposites," Journal of Thermal Analysis and Calorimetry, vol. 116, no. 1, pp. 265-272, 2014.

[17] K. C. Kim, B. Dai, J. K. Johnson, and D. S. Sholl, "Assessing nanoparticle size effects on metal hydride thermodynamics using the Wulff construction," Nanotechnology, vol. 20, Article ID 204001, 2009.

[18] T. Spassov, Z. Zlatanova, M. Spassova, and S. Todorova, "Hydrogen sorption properties of ball-milled Mg-C nanocomposites," International Journal of Hydrogen Energy, vol. 35, no. 19, pp. 10396-10403, 2010.

[19] P. Delchev, T. Himitliiska, and T. Spassov, "Microstructure and hydriding properties of ball-milled $\mathrm{Mg}-10$ at. $\% \mathrm{MmNi}_{5}(\mathrm{Mm}$ = La, Ce-rich mischmetal) composites," Journal of Alloys and Compounds, vol. 417, no. 1-2, pp. 85-91, 2006.

[20] E. Grigorova, M. Spassova, T. Spassov, and M. Khristov, "Hydrogen sorption properties of $90 \mathrm{wt} \% \mathrm{MgH}_{2}-10 \mathrm{wt} \% \mathrm{MeSi}_{2}(\mathrm{Me}=$ Ti, Cr)," Journal of Materials Science, vol. 49, no. 6, pp. 26472652, 2014.

[21] A. R. Yavari, J. F. R. de Castro, G. Vaughan, and G. Heunen, "Structural evolution and metastable phase detection in $\mathrm{MgH}_{2}$ $5 \% \mathrm{NbH}$ nanocomposite during in-situ $\mathrm{H}$-desorption in a synchrotron beam," Journal of Alloys and Compounds, vol. 353, no. 1-2, pp. 246-251, 2003. 



Submit your manuscripts at http://www.hindawi.com
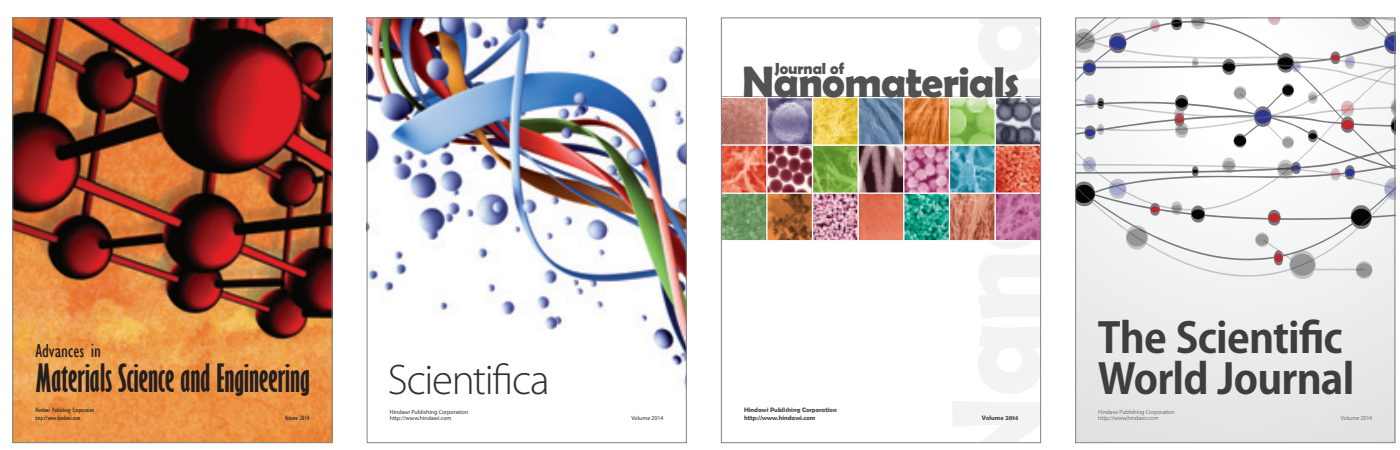

\section{The Scientific World Journal}
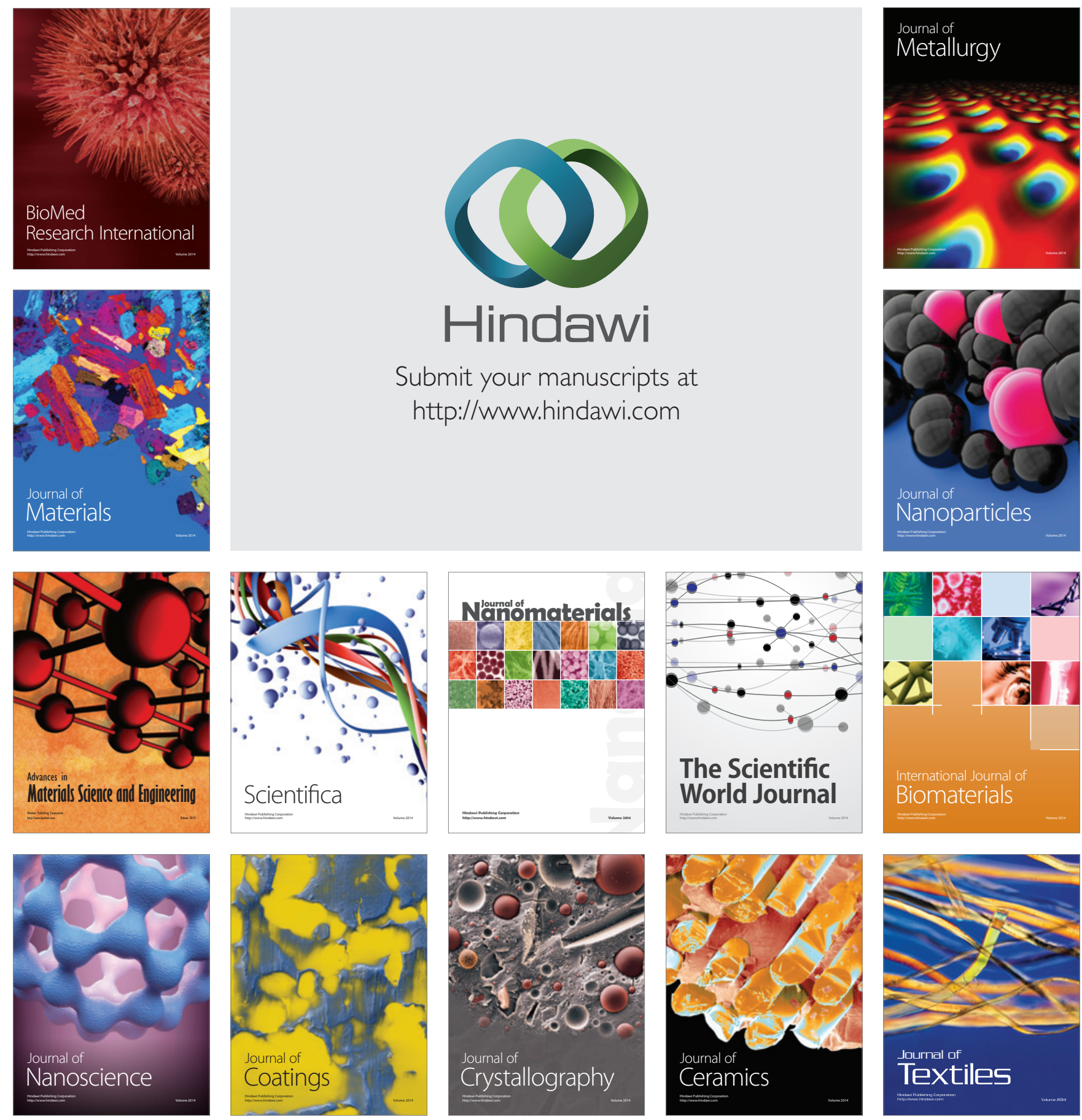